\title{
The pathologist in Ghana and potential for research
}

\author{
Jehoram T. Anim
}

\section{P. O. Box LG 748, Legon, Accra, Ghana}

Ghana Med J 2018; 52(2): 103-111 doi: http://dx.doi.org/10.4314/gmj.v52i2.7

Corresponding author: Professor J. T. Anim

Conflict of interest: None declared

E-mail: jtanim2000@yahoo.com

\section{SUMMARY}

One of the neglected areas of clinical medical practice in developing countries is the field of Laboratory Medicine. As a result, the important role of the laboratory physician in diagnosis of disease and subsequent management of patients is not much appreciated. Even more worrying is lack of appreciation of the research potential of laboratory medicine, considering that it provides a repository of confirmatory data on many human disorders; data that have been usefully employed for the study of various diseases in developed parts of the world. It is perhaps, the reason that many diseases peculiar to developing countries still remain untamed. My experience in the practice of anatomical pathology in several countries has taught me that the specialty, as with other specialties of laboratory medicine in Ghana needs more attention, with regards to its development to the level where it can meet its clinical functions satisfactorily. When this is ensured, it would also provide the necessary vital contribution to research that has characterised its practice in more advanced countries. More exposure of the specialty to undergraduate medical students must be encouraged in order to attract trainees into the specialty. Along with this exposure must go an increase in infrastructure and the necessary facilities to permit growth of the specialty. Research potential of the specialty must be harnessed and fully supported financially to help in unravelling peculiar disease problems of our locality. To achieve this, I have re-emphasised the need for a special fund to drive scientific research in Ghana.

Funding: None

Keywords: Pathologist, Laboratory Physician, Research, Funding.

\section{INTRODUCTION}

Several medical specialties remain obscure to nonmedical people and the specialty of pathology is one of these. The situation becomes more serious when even other health workers are unsure of, or even unaware of the activities of an important diagnostic specialty as pathology. To illustrate such state of affairs, I present herewith a conversation with a friend who by convention, may be regarded as well-educated and for whom I have a great deal of respect. We both studied in the University of Ghana and he became a lecturer in the same university, following a $\mathrm{PhD}$ in his chosen field. The conversation went as follows:

Q: So what kind of medical doctor are you now? A: I am a pathologist.

Q: A What? What do you mean by a pathologist?

A: Oh, a Laboratory Physician. You know, a doctor who specialises in Laboratory Medicine.

Q: I thought medical laboratories were run by technical staff, you know: technicians or technologists, or as they like to be called these days, medical laboratory scientists.
A: Medical/clinical laboratories have two main categories of personnel, in addition of course, to clerical and auxiliary staff. These are the Physicians or medically qualified personnel and the technical staff or laboratory scientists.

Q: But what do you do in the laboratories that the technical staff are unable to do?

Naturally, I proceeded to educate him on Laboratory Medicine and the Laboratory Physician, details of which I have presented later in this paper. However, the above exchange is meant to illustrate a gap in the knowledge of the general public about the types of personnel in the health care delivery team. The degree of ignorance on such matters, of course, should vary according to the person's background of formal education, and/or prior contact with medical personnel in general. Unfortunately, some health workers, including doctors also demonstrate poor knowledge about their clinical counterparts in the laboratories with whom they must interact for appropriate and efficient management of their patients. 
I was therefore, astonished when my wife narrated to me a discussion between her and a doctor friend. It went as follows:

\section{Q: Your husband is a pathologist, isn't he?}

A: Yes, of course! You must be familiar with what he was doing when he worked in Korle Bu Teaching Hospital in Accra, Ghana.

Q: Yes, I remember he was performing autopsies in addition to teaching medical students, but what would he be doing in Saudi Arabia? I am aware that autopsies are forbidden in Arab countries, so what is he doing there, apart from teaching in the Medical School?

A: Of course, he has a lot to do there. As far as I am aware, and I am a lay person, there are other facets to the job of a pathologist. According to him, he examines all biopsies and tissues taken from patients by the surgeon, gynaecologist and other doctors, provides them with the diagnosis and sometimes guides them in further management of their patients. In addition, he examines tissue fluids and smears for diagnosis; you know, the smear test that we women have been advised to do periodically. I am not sure of all the details of what exactly they do, but I know they make diagnoses on tissue and cell samples. This is in addition to a heavy teaching load of both undergraduates and postgraduates, including training of pathology residents, while also assisting in training of other clinical residents. He is really busy out there, you know.

The lack of knowledge on the part of the lay population about the specialty of Pathology is by no means peculiar to Ghana, or indeed Africa. However, it becomes serious when other medical colleagues display the level of ignorance illustrated above. The results of a recent survey on the UK public's perception of Pathology (Laboratory Medicine) reported in the July 2005 issue of Bulletin of the Royal College of Pathologists confirms that the negative perceptions may be universal ${ }^{1}$. According to the report, whereas $60 \%$ of the respondents knew that pathologists perform autopsies to find out causes of disease, only $9 \%$ knew pathologists were involved in diagnosis of cancer. When asked about a range of duties performed by doctors, only $50 \%$ thought pathologists were qualified doctors, while $37 \%$ thought pathologists work with only dead bodies. Whereas $27 \%$ knew pathologists help in treatment of patients with disease, only $22 \%$ thought pathologists were committed to improving public health in Britain. When asked to indicate which four health care personnel were most committed to improving public health in Britain only $12 \%$ chose pathologists, below government ministers and politicians $(17 \%)$. A similar survey carried out in Ghana or other African countries would prove very revealing indeed.
My late father worked in the Ghana Health Service as a Nurse/Dispenser during the British Colonial days, before Ghana became independent. I recall his reaction when I informed him in 1970 that I had decided to specialise in Pathology. He knew all about pathologists performing autopsies (having himself assisted at autopsies), but thought that was all they did. Indeed, in the 1930s and 1940s, the practice of pathology in the then Gold Coast was in its infancy, with the autopsy being the main recognised activity of the few expatriate pathologists in the country. Naturally, he wanted to know why I would not consider specialising in any of the more fashionable specialties of Surgery or Internal Medicine. After I had explained to him my interests and reasons for choosing Pathology, he began to understand that Medicine had moved on from the rudimentary practice he was familiar with in the 1930s and 1940s. Besides, in those days the rate of development of laboratory medicine service in general in Ghana, lagged behind that of many other countries. The early development of Laboratory Service in Ghana is well outlined in Addae's book on "The History of Western Medicine in Ghana: $1880-1960^{2}$. Interested readers are encouraged to read this excellent work.

\section{THE PATHOLOGIST/LABORATORY PHYSICIAN}

Who is the pathologist or laboratory physician? In this age of technology, the definition of a pathologist is readily available on the internet. The following is an adaptation of a definition available on the internet. https://www.prospects.ac.uk/job-profiles/pathologis

A Pathologist (Laboratory Physician) is a doctor who interprets and diagnoses the changes caused by disease in the body's cells and tissues. There are four distinct specialties within pathology:

- Chemical pathology/metabolic medicine Combines laboratory and clinical skills, using biochemical tests to diagnose and treat patients. With metabolic medicine, a sub-specialty of chemical pathology, the chemical pathologist treats patients where the chemical processes in the body do not function properly.

- Haematology - Diagnosis and treatment of disorders of the blood and bone marrow. The haematologist also provides clinical support for the haematology diagnostic laboratory, which includes the blood bank.

- Histopathology (Anatomical pathologist) Diagnosis and study of disease by medical interpretation of cells and tissue samples. The histopathologist's role is integral to cancer management through the staging and grading 


\section{Special Article}

of tumours. He also performs autopsies to determine details of disease processes and cause of death.

- Medical microbiology and virology - Diagnosis, treatment, management and prevention of infection in hospitals and the community. They also oversee the medical microbiology laboratory and provide a bridge between the laboratory and clinicians.

The definition above clearly states that the pathologist or laboratory physician is a physician with clinical responsibilities in the clinical laboratories. He differs from the laboratory medical scientist whose main function is to carry out and supervise laboratory scientific procedures. Depending on the country, the designation of pathologist may be preferred over laboratory physician. Thus, in the UK and Europe, the term pathologist is used for all physicians who specialize in any of the branches of laboratory medicine. In the USA, the term laboratory physician is preferred. As laboratory medicine has grown in stature, other specialties have been added and in some countries specialties like clinical immunology and molecular pathology have been added, especially within more academic settings.

The USA recognizes two broad categories of laboratory physicians, namely: anatomic pathologists and clinical pathologists; the latter to encompass chemical pathology, haematology with transfusion medicine and medical microbiology. Training of pathologists in the USA, therefore, follows these two pathways. On the other hand, in the UK and most European countries, pathologists are trained in the individual specialties mentioned above. Training of pathologists/laboratory physicians by both the West African College of Physicians and the Ghana College of Physicians and Surgeons follows a system similar to the UK and European models. Thus, pathology or laboratory medicine residents in this sub-region ultimately achieve a Fellowship in one of the four main specialties of pathology on completion of their training.

The various specialties of pathology have in common the function of scientific study of disease, employing laboratory-based methods which lead to diagnosis, elucidation of mechanisms involved in the disease process (pathophysiology and pathogenesis), as well as morphological and functional manifestations of the disease. In the process, they are also better placed to offer advice on and monitor further management of the disease.

They have played and continue to play an important role in the diagnosis and management of communicable diseases.
Currently, they also play an active role in the diagnosis and management of non-communicable diseases, notably various forms of cancer. The attributes of a pathologist have been discussed in my book; 'The Pathologist'. ${ }^{3}$

\section{THE GHANAIAN HISTORICAL PER- SPECTIVE}

Chapters 7 and 8 of Addae's book ${ }^{2}$ detail the establishment in the 1930s and 1940s, of the Medical Field Unit and Laboratory Service, both of which played fundamental roles in public health as well as curative medicine in the then Gold Coast. In those early years, the main emphasis on work in the few available medical laboratories was the investigation of the so-called Tropical Diseases; examples being tuberculosis, malaria and trypanosomiasis. However, by 1960, the clinical diagnostic aspect of the Laboratory Service had been established with its headquarters in Accra. The postindependence government of Dr. Kwame Nkrumah saw the need for more hospitals in the country and undertook the construction of larger medical centres in some regional capitals, notably Accra, Kumasi and SekondiTakoradi. The largest is Korle Bu Hospital in Accra which had seen considerable expansion from that built by the Colonial Governor, Guggisberg, in 1927. On completion of the expansion project it was equipped with up-to-date laboratories and a sizeable mortuary. In addition, the desire of Dr. Nkrumah's post-colonial government to pursue excellence in medical research led to the creation of the National Institute of Medical Research (NIMR) which was also located in Korle Bu. Both the Hospital and Research Institute were opened in the early 1960s and the latter was manned by both local and expatriate staff led by the South African scientist Dr. Joseph Gilman. The Ghanaians in the NIMR in the early years included: Dr. Butler (Biomedical Engineer), Mrs. Maude Cordylas (Nutrition Scientist) and several laboratory technicians among others. The Institute carried out research on various local disease problems including malaria, the haemoglobinopathies (notably, sickle cell disease), G6PD deficiency, trypanosomiasis and others. The Medical Field Unit which by this time, was fully manned by Ghanaians and still functional, was used for collecting material for research. The Institute also had an attached Animal Resource Centre which provided facilities for animal experimental research.

The operational level of the Institute was such that an American Research Team from the NIH, Bethesda, (headed by Dr. Richard Morrow) was attached to the Institute to carry out research into outbreaks of hepatitis in Ghana. 
Later, the study of the American team extended into the study of Burkitt's lymphoma which is also 'endemic' in Ghana. Dr. Francis Nkrumah, a Ghanaian paediatrician became involved in this study and later headed the project after the departure of the American team. The Burkitt's lymphoma project continues to this day, having been moved from the now defunct Research Institute to the Department of Child Health of Korle Bu Teaching Hospital. In the late 1960s the Research Institute was disbanded and the facilities taken over and utilised by the newly established Ghana Medical School to house some of its departments of the Pathological Sciences namely, the departments of Anatomical Pathology, Chemical Pathology and Microbiology. Haematology remained within the main Korle Bu Hospital complex, along with the Central Blood Bank.

\section{PATHOLOGY/LABORATORY MEDI- CINE IN KORLE BU HOSPITAL AND THE MEDICAL SCHOOL}

Prior to the establishment of the Department of Anatomical Pathology in the Medical School, the specialty was based in the mortuary, and its practice was largely autopsy based, with histopathology as a subsidiary service. The eminent pathologist of the then Gold Coast in the 1950s was Dr. GW Edington who later moved to the University of Ibadan, Nigeria in the 1960s to take up the Chair of Pathology in the new medical school. Thus, the archives of the Pathology Department of Korle Bu Hospital and indeed, many medical journals, contain publications by Dr. Edington on local Ghanaian diseases and syndromes.

In the early 1960s other pathologists who worked in that department included Dr. Kovi, who later moved to the US, and Dr. Edgcomb, who was part of the NIH team in Ghana. Ghanaian pathologists began to appear on the scene in the early 1960s, following their training abroad, mainly in UK, with the appointment of Dr. W.N. Laing as government pathologist in Korle Bu Hospital. Dr. Laing later became the Chief Pathologist. He was appointed Head of Department of Pathology of the new Medical School in 1965. He was soon followed by Dr. E.C. Christian, also an Anatomical Pathologist. Meanwhile, about the same time, the Department of Microbiology of the Medical School was being headed by Dr. S.N. Afoakwa, while Department of Haematology was still under the Ministry of Health with Dr. F. Boi-Doku in charge. A Hungarian expatriate, Professor Bela Ringelhann was in charge of the Department of Chemical Pathology in the Medical School. These formed the core of doctors in charge of Laboratory Medicine of Korle Bu Hospital, while also teaching the 'pathological sciences' to students of the new Ghana Medical School.
With the appointment of the two Ghanaian anatomical pathologists, histopathology service gained ascendancy, offering more efficient diagnostic service to Korle $\mathrm{Bu}$ Hospital.

In spite of the growth in histopathological service, the long held view by the general public that pathologists performed only autopsies still persisted, hence, the basis of the conversation at the beginning of this paper. This lack of knowledge on the activities of pathologists is not helped by the fact that undergraduate pathology teaching has become largely theoretical, with little or no exposure of medical students to laboratory practice of pathology. Whereas as undergraduate medical students in the 1960 s we were given class sets of microscopic slides to examine, together with examination of potted museum specimens during practical classes and were examined on these, pathology teaching nowadays relies heavily on projected gross and microscopic images. There is no direct student exposure to diagnostic pathology methods and students are not required to visit the clinical diagnostic laboratories. Attendance at autopsy which was mandatory for a two-week period during which students were required to perform some autopsies themselves, has been relegated to only a few days in the final year, which is often treated by students as optional. The situation may have been engendered by the larger classes that medical schools of today have to contend with. It may also be part of the changing pattern of undergraduate medical education which has relegated laboratory medicine in general to postgraduate level of training. The question to be addressed, though, is how to recruit medical graduates into laboratory medicine when they pass through their undergraduate education without exposure to what actually happens in the clinical laboratories. While not advocating a return to diagnostic bench work for undergraduate medical students, a case may be made for exposure to laboratory methods. This may take the form of periodic trips to the laboratories to encourage interactions with laboratory physicians and other laboratory staff, in institutions where this may not be the current practice. Undergraduate medical students may also be involved in multidisciplinary sessions as part of their curriculum, as happens in some medical schools where I have worked. Problem-based teaching methods, when properly conducted, are also meant to emphasise the role of various medical personnel in the diagnosis and management of the patient's condition. 


\section{THE PROBLEM OF ANATOMICAL PA- THOLOGY}

I wish to discuss further, anatomical pathology, simply referred to as Pathology in Ghana. This is a major medical specialty in the general discipline of Laboratory Medicine.

The aim is to highlight the chronic shortage of qualified pathologists, in addition to a still heavy autopsy load undertaken by them. The heavy autopsy load is because Korle Bu Teaching Hospital (KBTH), being the largest hospital in the country, also has the largest mortuary facility. As a direct consequence of this, the vast majority of medico-legal autopsies are done in KBTH, by the few trained pathologists, assisted by residents and a few other medical officers. The question to be answered is whether as the largest hospital of the country, KBTH must necessarily have the largest mortuary in the country to cater for all manner of deaths, whether hospital deaths or deaths in the community (which are mostly medico-legal). All these deaths housed in hospital mortuaries become the responsibility of the Department of Pathology, with no attempts to separate medico-legal deaths from hospital deaths. Would it not be more efficient to separate hospital pathology practice which must necessarily be diagnostic and management-oriented, from medico-legal autopsy for which the Coroner's institution must be developed in Ghana? Would it not be prudent to adopt best practices as seen in countries like the USA and the UK, where storage facilities, as well as personnel for carrying out medico-legal autopsies have been developed separately from the hospital, the prime purpose of which is to deliver health care and not storage facilities for medico-legal deaths? I have attempted to provide answers to some of these questions in earlier publications. ${ }^{4,5}$

Worldwide, hospital autopsy rates have fallen over the years, largely due to refinements in clinical diagnostic techniques (including histopathological and cytopathological techniques), which have contributed to improved ante-mortem diagnosis of many disorders. Thus, in other more developed parts of the world, hospital mortuaries have remained small enough to accommodate the dwindling numbers of hospital deaths. The focus of practice of pathology in those countries has become diagnostic and research. Therefore, the focus of pathology practice in Ghana needs to shift from the large autopsy load of which over $80 \%$ are medico-legal, to clinical diagnostic histopathology in order to ensure efficient diagnosis and management of patients, while also keeping abreast with developments in the specialty.

\section{TO WHAT EXTENT HAS PATHOLOGY INFLUENCED HEALTH POLICIES IN GHANA?}

As said earlier, autopsy studies by Edington in the 1950s established trypanosomiasis, haemorrhagic stroke and malaria, among others, as important causes of death in Ghana.

The 1960s work by Morrow and associates helped to define hepatitis A as a cause of epidemic hepatitis in Ghana. Studies of the African childhood jaw tumour in Ghana helped to define Burkitt's lymphoma as a peculiar form of malignancy. Later, the seminal autopsy study of Dr. WN Laing culminated in his landmark publication entitled "Sudden, Unexpected Causes of Death in Adults in Accra" $\%$. He also delivered an inaugural lecture to the Ghana Academy of Arts and Sciences in 1967 on the same subject. ${ }^{6}$ This work has succeeded in directing the attention of health planners to the common causes of unexpected death in adults in Ghana. The findings of Dr. Laing have recently been updated by Dr. A.B. Akosa, also a pathologist and former Director General of the Ghana Health Service. Dr. Akosa's findings were presented in an inaugural professorial address titled "Health of the Nation"" in which, in addition to discussing the numerous causes of ill health in Ghana, he re-emphasised the important causes of death in the Ghanaian population. A related study by a former head of department of pathology at the University of Ghana Medical School, Dr. Yao Tettey, entitled "What are the people of Ghana dying from?" 8 also analysed the causes of death in over 14,000 autopsies performed at the Korle $\mathrm{Bu}$ Teaching Hospital over a 3-year period.

In the 1970s and early 1980s Dr. E.C. Christian in his collaborative studies with Dr. A.K. Foli of the Department of Medicine \& Therapeutics also contributed immensely to the understanding of the pathology of liver diseases in Ghana. At the same time, pathologists also made journal publications on both prospective and retrospective studies of various other conditions. These publications have been largely from non-funded clinicopathological studies. I have personally participated (in the 1970s and early 1980s) in some of these studies and publications, in which we drew attention to the local pattern of certain diseases, such as: Hodgkin's and NonHodgkin's lymphoma, breast cancer, cancer of the cervix and many other disorders. On the basis of the information so collected by various pathologists, a cancer registry was started in 1970, which was based in Korle $\mathrm{Bu}$ Hospital. It is important to note that the value of any cancer registry is enhanced by pathological diagnosis. The same applies to any disease register and hence, the central role of pathology in medical practice. 


\section{Special Article}

Sadly, more recent advances in pathology techniques have not featured much in the diagnostic armamentarium of the Ghanaian pathologist. Thus, immunostaining which is now widely employed on routine basis in many histopathology laboratories, remains largely unexplored in Ghana.

Apart from a few markers of prognostic and disease management importance in breast cancer, the reagents are largely not available for diagnostic work in Ghana due to high costs. More advanced molecular tests which include nucleic acid based techniques such as, polymerase chain reaction (PCR) are already in routine diagnostic use in microbiology, clinical biochemistry and to some extent, haematology. In histopathology in the last few years, real-time PCR has come of age and microarray analysis technology is already in use in many pathology laboratories in developed countries for the diagnosis of various disorders. Together with in-situ hybridisation (ISH) techniques they are being employed to determine the expression of certain genes in many disorders. Known techniques such as interphase cytogenetics have been refined with in-situ hybridisation (ISH) which can more accurately diagnose genetic disorders as well as genetic alterations in various malignancies. From research origins of these techniques, various diagnostic kits have evolved, resulting in simplification of many pathological techniques. Greater emphasis on diagnostic histopathology by pathologists in Ghana, would ensure that these newer techniques are added to their diagnostic, as well as research capabilities in the country. Such a shift would also open avenues for research into many of the diseases that still exact a heavy toll on Ghanaians.

\section{PATHOLOGY AND RESEARCH}

Pathology has always played a pivotal role in medical research throughout the world, and Ghana should be no exception. Even purely clinical or epidemiological research often requires validation in one or more areas of laboratory medicine. It is a fact that centres of excellence in medicine usually have as their nerve centre a vibrant pathology institute. Examples include: The National Institutes of Health in the USA and its relationship with the Walter Reed Medical Centre and the Armed Forces Institute of Pathology; Johns Hopkins Medical Centre and the immense contribution of Pathology, specifically Dr. Welch to the stature of that institution in the USA; The Royal Postgraduate Medical School (now Imperial College) with its Wolfson Pathology Centre and Medical Research Centre in London, UK; and various Pathology Institutes and their affiliated hospitals in Europe, to mention some. Pathology in all these institutions has championed the cutting edge of medical research, leading to their worldwide acclaim.
Thus, training in research is increasingly featuring in various residency programmes for pathologists. This need has been advocated by eminent scientists such as Harris ${ }^{9}$ and Grisham. ${ }^{10}$ The role of research in the development of many diagnostic techniques in pathology has already been highlighted above.

The nature of the work of a pathologist is such that he is constantly involved in the collection, management and ensuring quality of data that can easily be used for research. ${ }^{3}$

The University of Ghana Medical School, in a modest way, has supported research into many disorders. One example is the part funding of my research project on "An autopsy study of stroke and other complications of hypertension in an adult Ghanaian population". This project was co-sponsored by the Wellcome Trust and the Ghana Medical School and has yielded data on the prevalence and severity of atherosclerosis in Ghanaian adults and its role in cerebrovascular disorders, as well as other factors that are involved in the pathogenesis of cerebral haemorrhage. The study also formed the basis of my MD thesis. The Department of pathology of the University of Ghana Medical School in KBTH, like all such departments elsewhere, is trying to break new grounds. Rudiments of molecular pathology techniques are being introduced in the study of diseases, sometimes with assistance from research centres such as, The Noguchi Memorial Institute of Medical Research (NMIMR) in Legon, but this has been limited by lack of adequate resources, including funding difficulties. Like any modern introduction into medicine, the costs of equipment and consumables are high. However, a start has been made, which must be nurtured and encouraged.

NMIMR which started as a joint venture between Ghana and Japan is currently almost completely manned by Ghanaian scientists who are carrying out research on locally relevant disorders, including malaria, childhood diarrhoeal diseases, HIV/AIDS, Buruli ulcer, as well as many other endemic and non-communicable diseases. Originally conceived and built as a nucleus around which medical research would grow, it was intended to be the research centre for the pathological sciences of the University of Ghana Medical School and the core of a Centre of Excellence. Over the years, the emphasis has moved to embrace all forms of medical research, both basic and clinical. Thus, in addition to research on communicable diseases, research is also ongoing in noncommunicable disorders including cancer, hypertension, diabetes, etc. In my view, more pathologists need to participate in research using the facilities available in the Institute. Hopefully, with increased funding, the original aim of creating a Centre of Excellence would materialise. 
The major bane of research in a developing country like Ghana has been lack of funding. Locally generated funds are woefully inadequate and funds from outside sources often come with conditions attached.

Many outside donors would rather collect materials from the poorer countries for research in already established laboratories outside, instead of providing research facilities to the poorer countries at the centre of the disease problem. The advantages of providing such facilities locally include the development of local expertise through technology transfer, as well as ensuring continuity of any project that is started through collaborative efforts.

It is for this reason that I am proposing the establishment of a separate National Fund for the Advancement of Scientific Research, which should be open to all researchers. Such a fund would ensure that research priorities are determined locally and strategies for their implementation worked out by local researchers, with the community as the prime beneficiary in mind. The current pervading situation where a foreign donor comes with their own agenda and in some cases, the sole aim of using local subjects to test various forms of therapy that may not necessarily be locally relevant or even affordable, may thus be avoided.

\section{SUGGESTED GHANA FUND FOR THE ADVANCEMENT OF SCIENTIFIC RE- SEARCH \\ Preamble}

In recent days, various political figures, as well as international personalities have called for increased research into nationally relevant issues, not least, the common diseases that afflict the general population. While it is true that the national government has done its best to provide research infrastructure and funds for many institutions, the input has been meagre at times. A lot of subvention and assistance have also been provided by various international sources. Most of these contributions have been made towards specific areas of research or health need. However, there is a need for a national body capable of determining and setting national priorities in all areas of research endeavour to which national and international resources can be applied. Such a body should ideally, be a governmental organization which is directly accountable to the Presidency and subject to all the regulatory mechanisms inherent in good governance. I am reliably informed that Parliament of the Republic of Ghana is currently working on a Bill along these lines.

\section{The mission of the suggested body}

This should include:

To establish a resource base for promoting research excellence through fostering a vibrant and resource-rich environment in which research activities in all relevant institutions and from all aspects of national life can thrive in Ghana.

The aims and objectives would include the following

- Complement and assist the activities of all existing research organizations in the country.

- Co-ordinate all fundraising activities in the country for the purposes of research.

- Actively solicit for resources from both national and international sources in order to create a buoyant reservoir of funds for creditable researchers to tap into for their respective activities.

- Establish national priority areas for research in consultation with all stakeholders.

- Establish national and international standards, including mechanisms for the approval of support for research proposals.

- Establish a credible and operable mechanism for the disbursement of funds for approved research.

- Establish a forum or forums for the propagation of results of research activities.

- Assist in establishing mechanisms for the application of the outcomes of various research activities.

- Provide other outlets for publication of research findings for the benefit of both national and international communities through journals and periodicals.

- Support the publication of proceedings of research activities in the form of books or electronic material.

\section{LOOKING INTO THE FUTURE}

Pathology service in Ghana, like other developing countries, still holds a lot of potential, but the way forward lies in more research. For example, many endemic diseases have been well described, but as at now, details of the pathogenesis of many of these diseases still remain elusive. As a result, no effective therapies or preventative measures, including development of effective vaccines, have been achieved. It must be remembered that pathology forms the bridge between basic and clinical sciences. Thus, the pathologist is best placed to translate basic science observations into clinical practice. ${ }^{10}$ Encouraging research in pathology is likely to enrich clinical practice in any medical institution. 


\section{Special Article}

Recent rapid technological advances have brought about monumental changes in biomedical science, an area which forms the bedrock of pathological science. Thus, in the U.K., there is a close relationship between the Institute of Biomedical Sciences and the Royal College of Pathologists.

Particular attention must be paid to the local development of molecular biology techniques that will help to transform the landscape of health care in Ghana. Here, I refer to the use of molecular biology methods to screen for inherited mutations predisposing to various diseases, be they communicable or non-communicable. Similar techniques can be used to test for response to drug treatment. Molecular methods are becoming available for the re-classification of diseases and elucidation of specific disease profiles that may facilitate targeted treatment. Thus, in future, it should be possible to classify diseases according to their responsiveness to tailored therapy. The difficulties in finding effective vaccines against common diseases like malaria, HIV infection and many more endemic diseases, or even cancer should rekindle our efforts in exploring the newer technologies.

The Ghanaian pathologist, as the laboratory physician, must continue to adapt to changing circumstances, both in medical education and in professional practice. Active clinical involvement is essential, in order to facilitate the transfer of basic science breakthroughs into clinical practice. In addition, definitive steps must be taken to educate the general public on the actual role of the pathologist in the medical team. Certainly, the public perception of the pathologist in Ghana must change, as must the attitude of other clinical colleagues towards the pathologist. To achieve this, pathologists themselves must work harder to make themselves clinically relevant, as has become the norm in more advanced countries. The diagnostic and audit nature of laboratory medicine must be made to feature more in clinical practice. Once the roles of all clinicians and their responsibility towards the patient have been clarified, such misunderstandings should be minimised.

As a first step, pathologists in Ghana must form a specialty grouping aimed at ensuring continuing professional development which must include quality assurance on a national scale and regular scientific and professional discourses. Out of these interactions, opportunities would emerge for collaborative research, as well as national policies on the introduction and utilization of newer scientific techniques to ensure modernization of pathology practice in the country.
It is my belief that such a grouping is likely to attract the attention of government, non-governmental organizations as well as other funding agencies that may be inclined to support research efforts into the large number of diseases that still burden the ordinary Ghanaian. There is always the tendency, and perhaps, rightly so, to overemphasise infections and infestations in Africa. What is now becoming evident is the fact that noncommunicable diseases such as, hypertension, diabetes, effects of atherosclerosis, cancer and other disorders associated with aging are becoming increasingly important in Ghana. Obesity, with all its associated disorders is just as important in Ghana as elsewhere in the world. There is a lot of research going on throughout the world in an attempt to understand the pathogenesis of these disorders and also to find cures for them. The genetic bases of some of these diseases are being exhaustively studied in order that gene therapy can be designed for them. Cancer research remains an ever growing field in which pathologists are actively involved. The role of environmental factors in the causation of various diseases is another expanding area of research. With obvious geographical and climatic differences between different parts of the world, something can be said for carrying out research into a particular disorder in a different environment, even if a lot is already known about the disorder in one specified locality. Thus, geographical pathology is essential for defining epidemiological aspects of any particular disease, be it communicable or non-communicable. It is my hope that the culture of clinical and basic medical research would be intensified in the Ghanaian medical community, especially among pathologists and also the scientific community at large. Many knowledgeable personalities have already called for more research into all spheres of life in Ghana.

\section{REFERENCES}

1. The Bulletin of the Royal College of Pathologists. 2006; 131 (July): 68-69.

2. Addae S. History of Western medicine in Ghana 1880-1960. Durham Academic Press. 1997, pp112130.

3. Anim JT. The Pathologist. Square One, Upton-onSevern. 1999.

4. Anim JT. Towards an improved pathology service in Ghana. Ghana Med J 2013; 47:40-45.

5. Anim JT. Autopsy practice in Ghana - Reflections of a pathologist. Ghana Med J. 2015; 49:112-119.

6. Laing WN, Sudden, unexpected causes of death in Ghana. Ghana Med J 1968; 7: 170-184.

7. Akosa AB. The Health of the Nation. Inaugural Professorial Lecture, University of Ghana. June 2000.

8. Tettey Y. What are the people in Ghana dying from? An analysis of 14,034 autopsies performed at the Korle $\mathrm{Bu}$ Teaching Hospital from 2001 to 2003. 
Newsletter of Ghana College of Physicians and Surgeons. 2005; 1(2).

9. Harris H. Where is pathology going? Guest Lecture, Pathological Society of Great Britain and Ireland. $147^{\text {th }}$ Meeting, 1983.
10. Grisham JW. The future of biomedical research and its impact on pathology. Arch Pathol Lab Med 1986; 110:289-295.

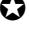

